\title{
IQ, expectations, and choice
}

by Francesco D’Acunto, Daniel Hoang, Maritta Paloviita and Michael Weber

No. 127 | JANUARY 2019

\section{WORKING PAPER SERIES IN ECONOMICS}

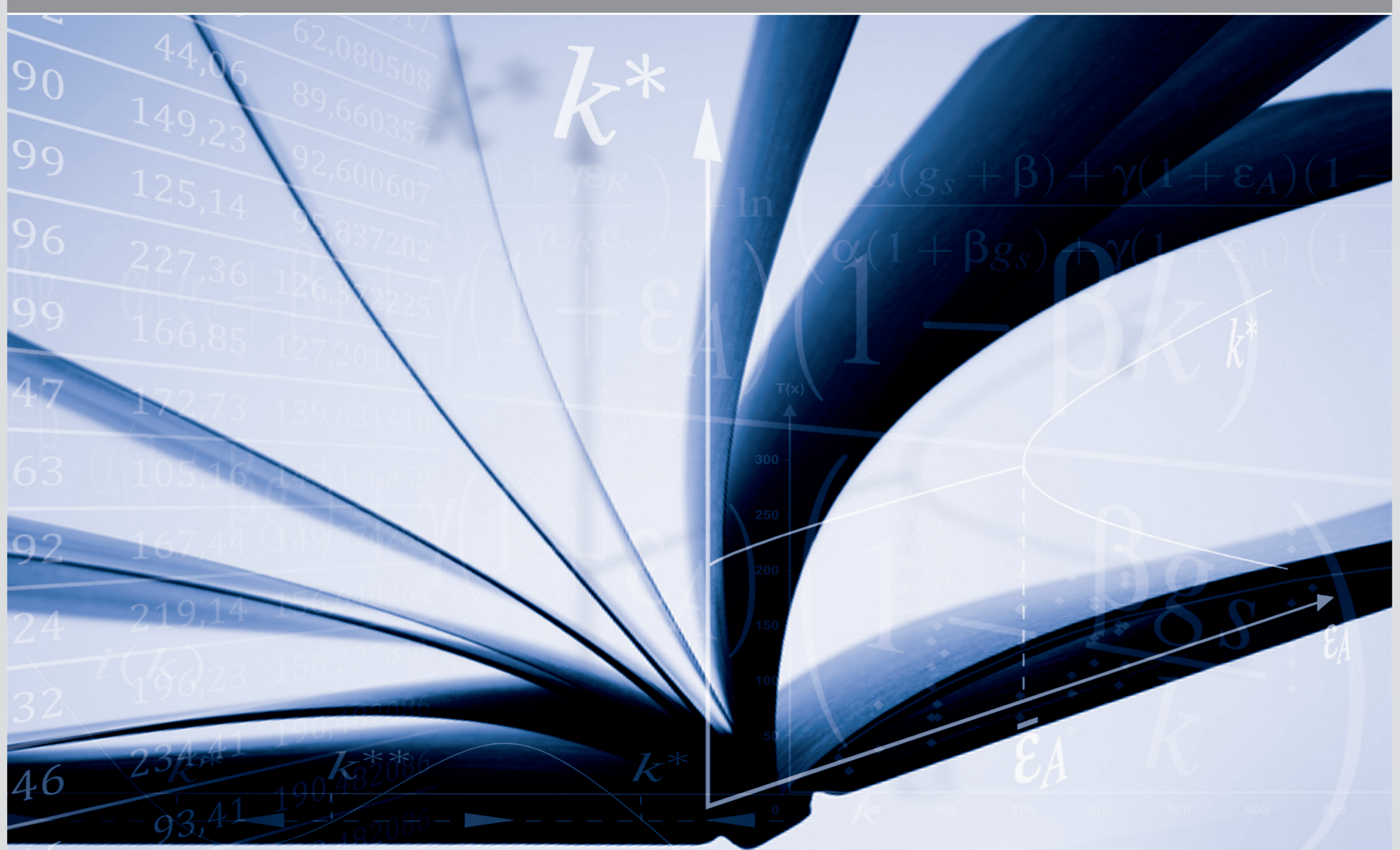




\section{Impressum}

Karlsruher Institut für Technologie (KIT)

Fakultät für Wirtschaftswissenschaften

Institut für Volkswirtschaftslehre (ECON)

Kaiserstraße 12

76131 Karlsruhe

KIT - Die Forschungsuniversität in der Helmholtz-Gemeinschaft

Working Paper Series in Economics

No. 127, January 2019

ISSN 2190-9806

econpapers.wiwi.kit.edu 


\title{
IQ, Expectations, and Choice*
}

\author{
Francesco D’Acunto, ${ }^{\dagger}$ Daniel Hoang, ${ }^{\ddagger}$ Maritta Paloviita,${ }^{\S}$ and Michael Weber ${ }^{\llbracket}$ \\ This version: January 2019
}

\begin{abstract}
We use administrative and survey-based micro data to study the relationship between cognitive abilities (IQ), the formation of economic expectations, and the choices of a representative male population. Men above the median IQ (high-IQ men) display 50\% lower forecast errors for inflation than other men. The inflation expectations and perceptions of high-IQ men, but not others, are positively correlated over time. High-IQ men are also less likely to round and to forecast implausible values. In terms of choice, only high-IQ men increase their propensity to consume when expecting higher inflation as the consumer Euler equation prescribes. High-IQ men are also forward-looking - they are more likely to save for retirement conditional on saving. Education levels, income, socio-economic status, and employment status, although important, do not explain the variation in expectations and choice by IQ. Our results have implications for heterogeneous-beliefs models of household consumption, saving, and investment.
\end{abstract}

\section{JEL classification: D12, D84, D91, E21, E31, E32, E52, E65}

Keywords: Behavioral Macroeconomics, Heterogeneous Beliefs, Limited Cognition, Expectations Formation, Household Finance.

${ }^{*}$ This research was conducted with restricted access to data from the Finnish Defence Forces and Statistics Finland. The views expressed here are those of the authors and do not necessarily reflect the views of the Bank of Finland, Finnish Defence Forces, or Statistics Finland. We thank the project coordinator at Statistics Finland, Valtteri Valkonen, for his help with the data and very insightful comments. We also thank Richard Blundell, Markus Brunnermeier, Doug Diamond, Mark Gertler, Simon Gilchrist, Zhiguo He, John Heaton, Erik Hurst, Luigi Iovino, Jessica Jeffers, Pascal Noel, Lubos Pastor, Monika Piazzesi, Raghu Rajan, Andrei Shleifer, Gianluca Violante, Rob Vishny, Amir Yaron, Luigi Zingales, Eric Zwick, and seminar participants at Aalto University, the Bank of Finland, CES-ifo Summer Institute: Expectation Formation, CES-ifo Workshop on Subjective Expectations and Probabilities in Economics, CEBRA Annual Meeting, CEPR Household Finance Conference, Symposium on Economics and Institutions, the European Central Bank, the EABCN Asset Pricing and Macro Conference, European Midwest Micro/Macro Conference, Federal Reserve Board, the ifo Institute, and the University of Chicago for valuable comments. We gratefully ackowledge financial support from the Deutsche Bundesbank. Weber also gratefully acknowledges financial support from the University of Chicago Booth School of Business, the Cohen Keenoy Faculty Research Fund at the University of Chicago Booth School of Business, and the Fama-Miller Center.

${ }^{\dagger}$ Carroll School of Management, Boston College, Chestnut Hill, MA, USA. e-Mail: dacuntof@bc.edu

${ }_{\ddagger}^{\ddagger}$ Department for Finance and Banking, Karlsruhe Institute of Technology, Karlsruhe, B-W, Germany. e-Mail: daniel.hoang@kit.edu

$\S$ Bank of Finland, Helsinki, Finland. e-Mail: Maritta.Paloviita@bof.fi

ॠBooth School of Business, University of Chicago, Chicago, IL, USA and NBER. e-Mail: michael.weber@chicagobooth.edu. 
After the rational-expectations revolution, researchers have largely stopped paying attention to how individuals form expectations, because subjective-expectations data display large cross-sectional variation and deviate from the rational benchmark (Manski (2004); Coibion, Gorodnichenko, and Kamdar (2018)). Yet individuals' actual expectations are central to explain their saving, consumption, and investment choices and hence aggregate outcomes (Gennaioli and Shleifer (2018)), which motivates a recent revival of studying how individuals form, update, and act upon economic expectations. ${ }^{1}$

Because forming expectations and financial decision-making require the use of cognitive resources, cognitive ability is a natural candidate to help explain the cross-sectional variation of individual expectations (Falk, Becker, Dohmen, Enke, Huffman, and Sunde (2018)). Cognition might affect individuals' ability to gather information about economic variables, their ability to solve maximization and resource-allocation problems over time, as well as their ability to grasp basic economic reasoning and intuition (D'Acunto, Hoang, Paloviita, and Weber (2018)).

Assessing the extent to which cognitive abilities shape individual expectations and decisions faces a major empirical challenge. The econometrician needs to jointly measure the cognitive abilities, economic expectations, economic decisions, and demographic characteristics of a representative population. To overcome this empirical hurdle, we match - to the best of our knowledge for the first time - individual-level administrative data on cognitive-ability (IQ) tests with survey-based information on a set of macroeconomic expectations, as well as on the consumption, saving, and borrowing plans of a representative sample of men in Finland.

Finland provides a desirable laboratory to study the effects of cognition on beliefs and choice, because it is a culturally homogeneous society with essentially free access to schooling and with a low degree of labor-income inequality (see Grinblatt, Keloharju, and Linnainmaa (2011)). As we discuss below, in this setting, the cross-sectional variation in cognitive abilities is barely associated with the variation in labor income, and hence assuming low-IQ individuals are low-income individuals and vice versa would be misleading. Moreover, the ratio of debt to labor income is stable around $80 \%$ across the distribution of cognitive abilities, which suggests men with different levels of IQ have not

\footnotetext{
${ }^{1}$ See also Landier, Ma, and Thesmar (2018), Ben-David, Fermand, Kuhnen, and Li (2018), Malmendier and Nagel (2016), Das, Kuhnen, and Nagel (2017), D'Acunto, Malmendier, Ospina, and Weber (2018), Bordalo, Gennaioli, and Shleifer (2018), and Gennaioli, Ma, and Shleifer (2018).
} 
only similar labor incomes, but also similar debt capacity and access to finance (D'Acunto et al. (2018)).

We use the Finnish setting to assess the extent to which cognitive abilities help explain the cross-sectional variation in individual-level economic expectations. In addition, we study the extent to which agents' economic and financial decisions react to their expectations based on heterogeneity in cognitive abilities.

We focus on inflation expectations because in most macroeconomic models, inflation expectations drive the consumption, saving, and borrowing decisions of individuals, workers' wage bargaining with firms as well as managers' price-setting decisions, and the effectiveness of fiscal and monetary policy, among other outcomes (Bernanke (2007)).

Figure 1: Mean Absolute Forecast Error for 12-Month-Ahead Inflation by IQ

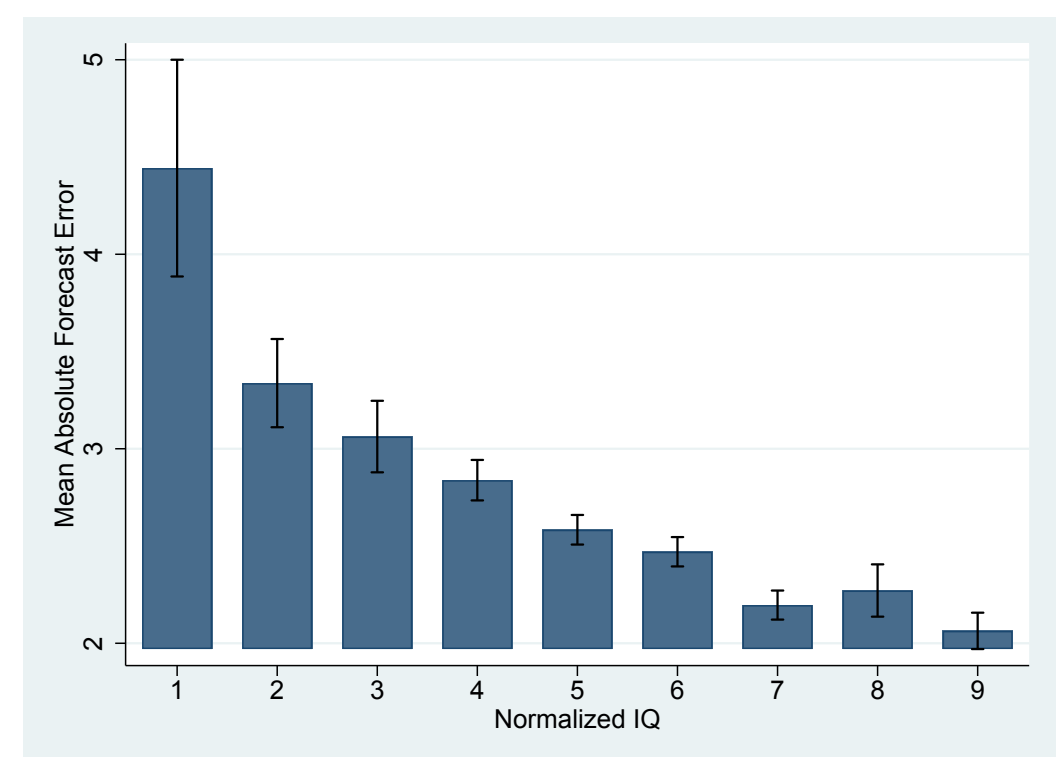

This figure plots the average absolute forecast error for inflation (in percentage points) across IQ levels. Forecast error is the difference between the numerical forecast for 12-month-ahead inflation and ex-post realized inflation. Vertical lines represent $95 \%$ confidence intervals around the estimated mean for each bin. IQ is the standardized test score from the Finnish Defence Forces. IQ obtains integer values between 1 and 9. The sample period is from January 2001 to March 2015.

Figure 1 plots the average absolute forecast error for inflation across bins by IQ-test scores. Forecast error is the difference between an individual's numerical forecast of 12-month-ahead inflation and actual inflation measured after 12 months. The average absolute forecast error for individuals with the lowest cognitive abilities is 4.3 percentage points. The absolute forecast errors decrease monotonically with IQ. The difference in absolute forecast errors between men with median cognitive abilities and men with the 
highest cognitive abilities is 0.6 percentage points, which is $30 \%$ of the forecast error of the highest-IQ individuals. Comparing 95\% confidence intervals across IQ levels, we can statistically and economically reject the null hypothesis of identical forecast error across most adjacent IQ levels. The average absolute forecast errors are large across the whole IQ distribution compared to the average realized inflation rate of $1.66 \%$ during our sample period and the official inflation target of the European Central Bank (ECB) of close to, but below, $2 \%$.

These cross-sectional associations are similar after we absorb time-varying economywide shocks at the monthly level, as well as a rich set of demographics that include age, income, education levels, socio-economic status, marital status, employment status, number of children, and rural versus urban residence. These demographics represent dimensions that earlier research has related to macroeconomic expectations, as well as potential determinants of households' consumption baskets, which researchers have shown affect the inflation expectations of Americans (D'Acunto, Malmendier, Ospina, and Weber (2018)). Consistent with earlier research, we find these observables are important determinants of expectations and choice, but they barely help explain the relationship between IQ and expectations.

Our IQ measure derives from administrative micro data (Grinblatt, Keloharju, and Linnainmaa (2011)). Around age 20, Finnish men take a standardized cognitive test immediately after starting their mandatory military service. IQ is a cohort-level standardized variable that follows a stanine distribution (integers from 1 to 9 , with 9 being the highest) and summarizes the results of 120 cognitive-ability questions in the military cognitive test. The Finnish Defence Forces (FDF) perform this level of aggregation and standardization to allow comparisons across cohorts. ${ }^{2}$ We observe this measure for all Finnish male cohorts between 1982 and 2001. We match IQ to the individual answers to the monthly harmonized European Commission Consumer Survey (EU survey), which covers repeated representative cross sections of Finns from 2001 to 2015. This survey elicits expectations of individual and aggregate economic outcomes, as well as propensities to consume, save, and borrow.

Our baseline analysis exploits cross-sectional variation, but the EU survey also contains a rotating panel dimension between 1995 and 1999 during which each individual is interviewed three times with a six-month lag between interviews. The panel allows us

\footnotetext{
${ }^{2}$ The standardization alleviates the Flynn effect of trending test scores over time.
} 
to study how IQ levels relate to the dynamics of inflation expectations within individuals. Realized inflation is highly persistent, and hence rational expectations imply on average a positive correlation between past inflation forecasts and current inflation forecasts (Landier, Ma, and Thesmar (2018)). We find only high-IQ men display a positive association between past and current inflation forecasts.

Moreover, under rational expectations, we would expect past expectations of inflation are positively correlated with current perceptions of realized inflation. This association should be especially detectable at times when no shocks or news about inflation are realized between adjacent interview periods. On average, we find an economically and statistically significant association for high-IQ men which is five times larger than the association for low-IQ men. In addition, the association for high-IQ men is indeed higher across interview periods with stable inflation but does not vary at all for low-IQ men.

After studying forecast errors and the consistency of expectations over time, we move on to consider other features of expectations that earlier research in microeconomics, macroeconomics, and social psychology proposed as signs of inaccuracy in elicited individual economic beliefs. In particular, we consider rounding - the tendency of households to respond with multiples of 5 when asked for a numerical forecast of inflation - and the reporting of implausible values for expected inflation (see, e.g., Manski and Molinari (2010) and Binder (2015)).

Figure 2: Rounding and Implausible Values for Inflation Expectations by IQ
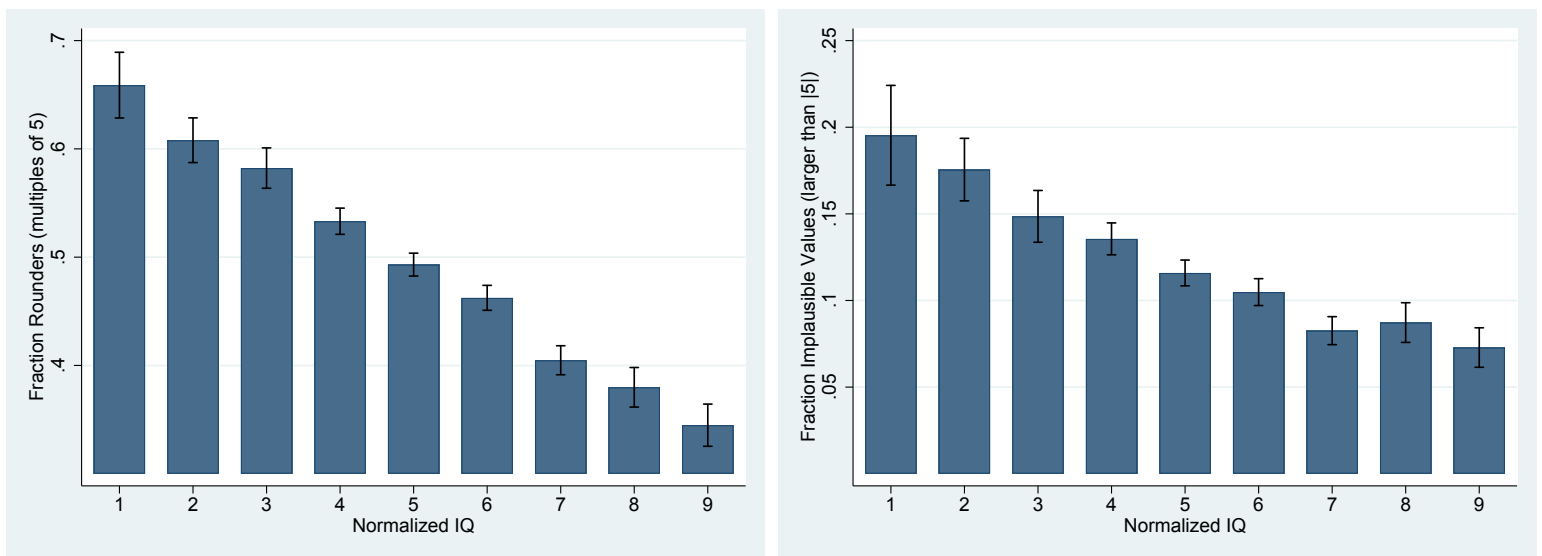

This figure plots the share of rounders (left panel) and the share of survey respondends who report forecasts for inflation larger than 5 in absolute value across IQ levels. We define rounders as survey participants who report multiples of 5 for the numerical forecast for 12-month-ahead inflation. Vertical lines represent 95\% confidence intervals around the estimated mean for each bin. IQ is the standardized test score from the Finnish Defence Forces. IQ obtains integer values between 1 and 9. The sample period is from January 2001 to March 2015. 
Figure 2 plots the average share of respondents who round (left panel) and the average share of respondents who provide implausible values (right panel) by IQ bins. ${ }^{3}$ The figure documents two monotonic patterns for the shares of rounders and those providing implausible inflation forecasts across IQ bins. For both aspects of forecast inaccuracy, the monotonic patterns are similar to the one we documented in Figure 1 for forecast errors.

In the second part of the paper, we assess whether the heterogeneity of individual expectations by IQ levels matters for economic decision-making. As a first step, we assess whether IQ levels relate to Finnish men's understanding of intertemporal substitution. Specifically, we test whether individuals adjust their durable consumption plans to their inflation expectations as the consumption Euler equation prescribes, after keeping constant income expectations and other macroeconomic expectations (Bachmann, Berg, and Sims (2015)). The consumer Euler equation is at the core of all dynamic macro models, and many central banks relied on the Euler equation when implementing policies to raise inflation expectations during the Great Recession in the hope of stimulating consumption. $^{4}$

Because the numerical inflation expectations of low-IQ individuals are inaccurate and such individuals might be aware of their inability to forecast inflation precisely, one might expect they actively decide not to employ their numerical inflation expectations when forming purchasing plans. We thus follow D'Acunto, Hoang, and Weber (2018) and create a qualitative measure of inflation expectations - a dummy variable that equals 1 when a household expects inflation to increase over the next 12 months relative to the previous 12 months. D'Acunto et al. (2018) show this qualitative measure tracks closely ex-post inflation rates even for individuals with low levels of sophistication. If low-IQ individuals were aware of their biases and understood intertemporal substitution, we would expect that at least their accurate qualitative inflation expectations were related to their purchasing plans.

When focusing on high-IQ men, we find respondents who think inflation will increase in the following 12 months are almost $4 \%$ more likely to state it is a good time to purchase

\footnotetext{
${ }^{3}$ In this figure, we consider forecasts whose absolute value is larger than 5 as implausible values. As we show below, the results are similar when we change this threshold.

${ }^{4}$ Yellen (2016) is a good example: "With nominal short-term interest rates at or close to their effective lower bound in many countries, the broader question of how expectations are formed has taken on heightened importance. Under such circumstances, many central banks have sought additional ways to stimulate their economies, including adopting policies that are directly aimed at influencing expectations of future interest rates and inflation."
} 
large-ticket items relative to other high-IQ men. Instead, when limiting the sample to low-IQ men, we detect a small, negative, and statistically insignificant association between qualitative inflation expectations and readiness to spend. These results hold conditional on the rich set of demographics discussed above and suggest that even if low-IQ men held plausible inflation expectations - for instance, because policymakers successfully anchored expectations or provided information about professional forecasts - low-IQ men might still not behave in line with the predictions of standard macroeconomic models.

We find high-IQ men react to their inflation expectations but low-IQ men do not also when splitting the sample by several demographic characteristics. A notable exception are respondents who have an economics or business degree. In this subsample, even low-IQ individuals who expect higher inflation increase their readiness to spend as predicted by the consumer Euler equation.

One might worry low-IQ men are more likely to be financially constrained than high-IQ men, which would explain the insensitivity of their consumption plans to changes in real interest rates (see Zeldes (1989)). Conditioning on labor income does not affect any of our baseline results, and low-income individuals are plausibly more likely to be financially constrained than high-income individuals. Another potential concern is that expecting higher economic growth and hence higher household income might deliver a spurious positive relationship between the propensity to spend and inflation expectations. D'Acunto et al. (2018) directly show financial constraints and income expectations elicited at the same time as inflation expectations cannot explain the non-response in the consumption plan of low-IQ men to their inflation expectations.

In the last part of the paper, we consider households' saving and borrowing motives, even if we can only observe these dimensions for a restricted portion of our sample. We find that high-IQ and low-IQ men do not differ in their propensity to save part of their monthly income - if anything, high-IQ men are less likely to save in general. High-IQ men, though, are more likely to save for retirement relative to saving for current purposes. These results suggest high-IQ men might understand the trade-off between current consumption and future consumption better than low-IQ men (Falk et al. (2018)). Moreover, high-IQ men are as likely as low-IQ men to borrow to finance current consumption, but high-IQ men are more likely to borrow to finance current or future education-related costs. Overall, we interpret these results as consistent with high-IQ men being more forward-looking than low-IQ men. 
Our findings stress the importance of cognitive abilities in shaping individual economic decision-making. Papers that document the role of IQ in financial decision-making are Grinblatt et al. (2011), who study the effect on stock market participation, Grinblatt, Keloharju, and Linnainmaa (2012), who study the effect on trading behavior, and Grinblatt, Ikäheimo, Keloharju, and Knüpfer (2016), who study mutual fund choice. Agarwal and Mazumder (2013) relate cognitive abilities to suboptimal use of credit cards and home-equity loan applications. Aghion, Akcigit, Hyytinen, and Toivanen (2017) use micro-level data on visuospatial IQ to study the effects of cognitive abilities, education, and parental income on inventiveness. Dal Bo, Finan, Folke, Persson, and Rickne (2017) relate IQ to the likelihood individuals enter political careers in Sweden. In a broad, comprehensive, and representative study of global preferences, Falk et al. (2018) document the relationship between survey respondents' self-reported cognitive abilities and their economic preferences.

We focus our study on how individuals form inflation expectations and whether they adjust their consumption, savings, and borrowing plans to their inflation expectations because the consumer Euler equation, and hence, inflation expectations, is at the core of all modern models in macroeconomics and finance. Other recent contributions studying the formation and updating of inflation expectations and the relationship with economic behavior are Malmendier and Nagel (2016), who relate lifetime inflation experiences across cohorts to inflation expectations, Coibion, Gorodnichenko, and Kumar (2018), who study how firms form inflation expectations, Bachmann et al. (2015), who are the first to study the consumer Euler equation at the micro level, Crump et al. (2015), who study the consumer Euler equation using the microdata from the novel Survey of Consumer Expectations from the New York Fed, D'Acunto et al. (2018), who causally relate inflation expectations to consumption plans using preannounced consumption tax changes, D'Acunto et al. (2018), who show individuals extrapolate from the realized inflation experienced in their shopping bundle to overall inflation expectations, and Coibion et al. (2019), who study how different forms of monetary policy communications causally change individuals' inflation expectations. None of these papers focuses on the heterogeneity in how agents form expectations by cognitive abilities. 


\section{Data}

Our analysis uses three micro data sets that include individual-level information on macroeconomic expectations, consumption and borrowing plans, and cognitive abilities, as well as administrative information on household-level income.

\section{A. Data on Cognitive Abilities}

Finland has general conscription for men, which means that all Finnish men between the ages of 18 and 60 are liable for military or non-military service. The share of men who do non-military service is only about $3 \%$ of all men who start military service. ${ }^{5}$ Within the first weeks of the mandatory military service, Finnish men typically around the age of 19-20 have to participate in a series of tests. The FDF administers these tests and uses the results to select candidates for possible officer training. Because ranking well in the IQ test provides a set of advantages in terms of quality of training and access to elite social networks, men have an incentive to perform as well as possible on the test (Grinblatt et al. (2011)).

The cognitive-ability test consists of 120 questions that focus on three areas visuospatial, mathematical, and verbal. The FDF aggregates those scores into a composite measure of cognitive abilities, which we label collectively as IQ. The FDF standardizes IQ to follow a stanine distribution. Stanine (STAndard NINE) is a method of scaling test scores on a 9-point standard scale with a mean of 5 and a standard deviation of 2 , approximating a normal distribution. The respondents with the lowest $4 \%$ of test scores are at least 1.75 standard deviations from the mean and are assigned a standardized IQ score of 1 , and the $4 \%$ with the highest test scores are assigned a standardized IQ score of 9 . Hence, most of the mass of our observations is around the median bin, whereas the extreme bins account for only a small part of the sample. We have test results for all participants from 1982 until 2001.

Finland is a homogeneous country in terms of cultural background and opportunities. Access to education, including college education, is virtually for free. The country is also racially homogeneous (Grinblatt et al. (2011)). These features make the Finnish setting a desirable laboratory because our measures of IQ are unlikely to proxy for differences in cultural or environmental factors individuals could manipulate, but are more likely to

\footnotetext{
${ }^{5}$ Please see https://puolustusvoimat.fi/en/conscription for these and additional details.
} 
reflect differences in innate abilities across individuals.

\section{B. Data on Expectations, Spending, and Borrowing Plans}

Our main source of information on individual-level macroeconomic expectations and consumption and borrowing propensities are the confidential micro data underlying the Consumer Survey of Statistics Finland. Statistics Finland conducts the survey on behalf of the Directorate General for Economic and Financial Affairs of the European Commission as part of the European Commission's harmonized consumer survey program. ${ }^{6}$ Every month, it asks a representative repeated cross section of approximately 1,500 Finns questions about general and personal economic conditions, inflation expectations, and willingness to spend on consumption goods. Statistics Finland also collects additional information through supplementary questions on plans to save and borrow.

We obtained access to the micro data underlying the survey for the period starting in March 1995 and ending in March 2015. Until December 1999, Statistics Finland ran the survey using rotating panels as opposed to repeated cross sections. In the rotating panels, the same person within a household answered the survey three times at six-month intervals, and each month one-third of the sample was replaced. Since January 2001, the survey has employed random samples that change completely from month to month. ${ }^{7}$ The samples are drawn from the total population of 4.4 million individuals and 2.6 million households residing in Finland. The survey is run through phone interviews. In advance of the phone interview, Statistics Finland notifies all target individuals with a letter that contains information about the contents and logistics of the survey. Our analysis employs the purely cross-sectional data starting in 2001 with the exception of Section II.B., in which we exploit the panel dimension to study variation within individual over time.

We use the answers to the following two questions in the survey to construct the variables capturing spending plans and inflation expectations in our baseline analysis:

\footnotetext{
${ }^{6}$ D'Acunto et al. (2018) use the micro data for several European countries and discuss in detail the survey design and data properties.

${ }^{7}$ The data for 2000 are missing, unfortunately.
} 
Question 10 In view of the general economic situation in Finland, do you think that now it is the right moment for people to buy durable goods such as furniture, home appliances, cars, etc.?

Respondents can answer, "It's neither a good nor a bad time," "No, it's a bad time," or "Yes, it's a good time."

Question 7 By what percentage do you think consumer prices will change over the next 12 months?

Respondents can answer numbers between -100 and 100 with one decimal point.

In addition, we use qualitative questions regarding expectations about general macroeconomic variables, personal income and unemployment, and a rich set of socio-demographics from Statistics Finland, which include gender, age, marital status, household size, and education levels.

\section{Data on Income from Tax Returns}

We also have access to administrative income and debt data for all Finnish full-time residents at the end of each calendar year through Statistics Finland. The data contain information on individuals' labor and business incomes, received and paid income transfers, as well as overall household taxable assets and liabilities. The information is collected from underlying sources across various agencies (Tax Administration, National Institute for Health and Welfare, Statistics Finland, Kela), administrative registers, and statistical repositories.

\section{Descriptive Statistics}

Table 1 contains the descriptive statistics for the main variables in our analysis. Mean inflation expectations during our cross-sectional sample are $2.5 \%$ with large cross-sectional dispersion of $3.76 \%$. Mean household income is EUR 22,500 and the average age is 30.7 years. $5.8 \%$ are unemployed in our sample, $60 \%$ are single, but $77.6 \%$ have children. In our running sample, $35.6 \%$ of men live in urban areas with $27.8 \%$ living in Helsinki and $34 \%$ have a college degree. 
On average, $51 \%$ of respondents say it is a good time to buy durables, $20 \%$ say it is a bad time, and the others are indifferent. On average, $72 \%$ of men save in general and $29.5 \%$ save for retirement. $15 \%$ of Finns borrow money for education and $31.3 \%$ borrow for consumption.

Table 2 reports average inflation expectations and standard deviations within each stanine of the distribution by IQ. Both the mean and the cross-sectional dispersion in inflation forecasts are higher for low-IQ men than for high-IQ men and decrease monotonically in IQ. Note the number of observations is not symmetric around bin 5 , but we observe systematically lower mass in the left tail of the distribution than in the right tail. In some of our analysis, we split our sample between groups 1 to 5 (low-IQ mean) and groups 6-9 (high-IQ men) to obtain subsamples of similar size.

\section{IQ and Expectations}

The first part of our analysis tests whether any systematic heterogeneity exists in the precision and consistency with which economic agents form their inflation expectations based on cognitive abilities. We also assess the potential heterogeneity in the relationship between expectations and IQ by demographic splits, and we study the association between past forecasts of inflation, current forecasts of future inflation, and current inflation perceptions by exploiting the panel component of the survey.

\section{A. Cross-sectional Expectations and Forecast Errors}

We start by analyzing the association between IQ levels and the precision and accuracy of inflation expectations in the raw data. First, we compute the forecast error for inflation at the individual level as the difference between the numerical forecasts for 12-month-ahead inflation and ex-post realized inflation. The forecast error for inflation is a proxy for the accuracy of households' inflation expectations - the higher the forecast error, the lower the accuracy of forecasts.

\section{A.1 First Moment of Expectations}

In Figure 1 in the Introduction, we compute the average of the absolute values of the individual forecast errors within each stanine of normalized IQ scores. The 
graph documents a monotonic negative association between forecast errors in inflation expectations and cognitive abilities. Men in the lowest IQ stanine have an average absolute forecast error of about $4.4 \%$, whereas men in the highest stanine have an absolute forecast error of about $2 \%$, which is more than $50 \%$ smaller. Two patterns are worth noticing. First, the monotonic relationship between absolute forecast errors and cognitive abilities is non-linear, and cognitive abilities display a decreasing marginal improvement on forecast errors. Second, respondents with the lowest cognitive abilities are not the only drivers of the patterns in the data. In fact, Figure 1 shows that individuals just below the median stanine (4) display forecast errors that are more than $40 \%$ higher than individuals in the top stanine.

We repeat the analysis for the bias in forecasts - the mean forecast error. In this alternative definition, we allow for positive and negative deviations of inflation expectations from ex-post realized inflation to wash away. Figure 3 reports the results for the alternative definition of forecast errors, and replicates all the patterns in Figure 1, although the association is slightly flatter for levels of IQ above the median.

The univariate association between IQ bins and forecast errors might proxy for other individual-level characteristics, and especially for income or education levels. In fact, IQ bins and taxable income might be positively associated, but we find the correlation between IQ and income levels, despite being positive, is quite low (0.15).

To assess the extent to which this interpretation might be relevant in our setting, we first repeat the univariate analysis of Figure 1, plotting average forecast errors across categories of income and education level. In Panel A of Figure 4, we split our sample into nine equal-sized bins of income and report the average forecast errors for individuals in each bin. Notably, we fail to detect any monotonic association between the average forecast error and income levels. If anything, average errors are higher for the income levels above the median - with the notable exception of the top percentile - than for the income levels below the median. These results underscore the desirability of the Finnish setting which allows us to disentangle the variation in cognitive abilities from the variation in labor income.

Panel B of Figure 4 reports a similar analysis for splitting the sample into six groups based on education levels. We follow the International Standard Classification of 
Education to construct the six groups. ${ }^{8}$ We fail to detect a negative association as stark as the one by the IQ bins between education levels and average forecast error, although the association is slightly negative. These results suggest variation in IQ levels exist among individuals that obtain the same formal degree. The overall amount of learning of individuals holding the same degree but different levels of IQ might differ, but at least in terms of observable levels of education, we do not detect substantial differences in forecast errors.

Our analysis of the raw data suggests the potential of observed characteristics to explain the association between forecast errors and IQ is low. For a direct test, we perform a multivariate analysis in which we regress individual-level forecast errors on a dummy variable that equals 1 if the individual belongs to the top four stanines of the normalized IQ distribution (6 to 9), and zero otherwise, year-month fixed effects and a rich set of demographics. Demographics include age, age ${ }^{2}$, a dummy that equals 1 if the respondent is single and 0 otherwise, log of income, a dummy that equals 1 if the respondent has a college degree and 0 otherwise, an unemployment dummy, a dummy that equals 1 if the respondent has at least one child and 0 otherwise, a dummy that equals 1 if the respondent lives in a urban area and 0 otherwise, and a dummy that equals 1 if the respondent lives in Helsinki and 0 otherwise. On average, the mean absolute forecast error is 0.25 -percentage-points lower for high-IQ men relative to low-IQ men (see column (1) of Table 3).

To further investigate the role of observables in shaping the relationship between IQ and expectations, we perform the multivariate analysis across a set of sample splits in Table 3. We first aim to capture the potential differences in households' consumption baskets related to observables. Household consumption baskets, and especially the price changes households observe for the goods they typically purchase, are important determinants of expectations about general inflation (D'Acunto et al. (2018)). We compare the size of the association between IQ and absolute forecast errors for inflation separately for single and married respondents (column (2)), respondents below and above age 35 (column (3)), urban and rural respondents (column (4)), and respondents earning more than the median labor income in the sample (column (5)).

\footnotetext{
${ }^{8}$ The classification includes eight categories with the first two categories not present in our sample. The categories are: primary education (1), lower secondary education (2), upper secondary education (3), post-secondary non-tertiary education (4), short-cycle tertiary education (5), bachelor (6), master (7), and doctoral (8).
} 
Across the board, we find IQ is economically and statistically negatively associated with the absolute forecast errors for inflation within each sample split. In terms of heterogeneity across groups, some differences in the association between IQ and forecast errors are noteworthy, even though we typically fail to reject the null hypothesis that the point estimates across splits are equal. High IQ is associated with a larger reduction in forecast errors within young respondents than within old respondents. Even though our paper is agnostic about the driving force behind that result, one potential explanation could be cognitive abilities deteriorate with age. We observe IQ around age 20 for all respondents and we might expect that within our sample, some men that were in the top part of the IQ distribution when they took the test have lower cognitive abilities at the time of the survey. We also observe a stronger effect of IQ on forecast errors within high-income men and men living in rural areas.

The second set of splits we consider refer to proxies for the extent to which households might find it easy to obtain information about inflation and the extent to which households understand basic economic concepts. We estimate the baseline specification for respondents with or without a college degree (column (6)), and respondents with a degree in the areas of economics, business, law, or information, and other respondents (column (7)). We find the association between IQ and absolute forecast error for inflation is about half the size for college-educated respondents and respondents with economic-related degrees than for others. This result suggests the ability to process information or the grasping of basic economic concepts might be a substitute for cognitive abilities when forming expectations about inflation. At the same time, IQ is still economically and statistically significantly negatively associated with absolute forecast errors for inflation even for respondents who are more educated or have economics-related degrees.

Overall, the association between IQ and forecast errors for inflation is a stable feature of the data. Some heterogeneity exists by demographic splits, which is why the subsequent analysis partial out these variables to ensure they do not drive any results.

\section{A.2 Second Moment of Expectations}

All the results we have discussed so far refer to the first moment of the distribution of inflation expectations across IQ levels. Research in economics and finance suggests dispersion in forecasts might proxy for differences in opinions across forecasters (Roth 
and Wohlfart (2018) and Diether, Malloy, and Scherbina (2002)). Hence, one might ask whether the second moment of inflation expectations also varies across levels of IQ, that is, whether the standard deviation of the reported inflation forecasts is systematically higher within low-IQ bins than within high-IQ bins. Higher dispersion of expectations for low-IQ respondents would be consistent with low-IQ respondents being less certain, more confused, disagreeing more, or less capable of providing precise estimates than high-IQ respondents.

In Figure 5, we report the average standard deviation of the forecast errors for inflation across IQ bins. Indeed, we detect a negative monotonic relationship between the dispersion in forecast errors and IQ levels that mimics the pattern for the first moment of the distribution. As expected, the pattern we detect for the cross-sectional dispersion in forecast errors by IQ is similar to the pattern in the standard deviation of forecasts by IQ (Table 2) because the time-series variation in realized inflation is small compared to the variation in expectations across men.

\section{B. Consistency of Expectations within Individuals}

Our results so far exploited cross-sectional variation in cognitive abilities and inflation expectations for individuals we observe only once. Between 1995 and 1999, though, Statistics Finland administered the survey with a panel component. In this section, we use the panel component to study how past inflation expectations are associated with current inflation expectations, as well as how perceptions of the current inflation rate, which the EU survey also elicits, relate to past inflation expectations within individuals.

In the standard model, agents have forward-looking expectations, that is, only news relevant for future inflation should result in forecast revisions. Moreover, many central banks aim to anchor inflation expectations. Hence, under rational expectations we would expect on average a positive correlation of inflation expectations within individuals over short periods of time. Columns (1) and (2) of Table 4 investigate this auto-correlation of inflation expectations for high-IQ and low-IQ men when we condition on demographics and year-month fixed effects. An economically and statistically significant correlation of $23 \%$ exists for high-IQ men. This partial autocorrelation is statistically insignificant and close to zero $(2.5 \%)$ for low-IQ men.

Under rational expectations, we would also expect, on average, past inflation 
expectations should be consistent with current perceptions of inflation. For this test, we regress current inflation perceptions on past inflation expectations at the individual level. In columns (3) and (4) of Table 4, we detect a positive and statistically significant association of $24 \%$ between current inflation perceptions and past inflation expectations for high-IQ men. The association for low-IQ men is statistically significant but an order of magnitude lower than the association for high-IQ men (5\%).

Under rational expectations, the correlation between current perceptions of inflation and past expectations should be lower in periods with shocks to realized inflation. ${ }^{9}$ To corroborate our interpretation of this result, we split the sample into periods in which the difference between the inflation rate at the time of the first and subsequent interview is in the top third of the distribution and all other periods. In columns (5) and (6) of Table 4 , we repeat the analysis only for periods of low changes in inflation, whereas in columns (7) and (8) we study periods with larger changes in inflation. Comparing columns (5) and (7), we indeed find the positive association between past inflation forecasts and current perceptions of inflation is higher during periods of stable inflation than during other periods for high-IQ men. To the contrary, columns (6) and (8) show that no differences exist in the economically small association for low IQ men. If anything, the association appears slightly larger during periods of changing inflation, which seems barely consistent with rational expectations.

We interpret these within-individual results as suggesting that the dynamics of expectations of high-IQ men are more consistent with the rational benchmark than those of low-IQ men.

\section{Rounding and Implausible Values}

In the last part of the analysis on how IQ shapes the expectation formation of individuals, we consider two dimensions that earlier research related to the quality of forecasts.

The first dimension is rounding, that is, individuals' tendency to report values that are multiples of 5 when asked to provide numerical forecasts. Previous research has argued reporting round numbers conveys uncertainty about future inflation (e.g., see Binder (2017) and Manski and Molinari (2010)). The second dimension is individuals'

\footnotetext{
${ }^{9}$ We should not expect an attenuating effect of shocks to realized inflation on the autocorrelation of inflation expectations to the extent expectations are fully forward-looking and shocks to realized inflation do not affect long-run inflation.
} 
tendency to report implausible values, that is, values that are unlikely to occur based on historical inflation rates and professional forecasts.

\section{C.1 Rounding and Inflation Uncertainty}

Figure 2 in the Introduction plots the fraction of respondents who report multiples of 5 in their numerical forecasts across the 9 bins of IQ. Similar to the baseline association of forecast errors for inflation with IQ, we document a monotonic negative association between the fraction of rounders and IQ bin. This fraction ranges from $65 \%$ for respondents in the lowest IQ bin to $35 \%$ for respondents in the highest IQ bin. Figure 2 shows we can also reject the null hypothesis that the fractions of rounders are the same across almost all adjacent IQ bins, which suggests respondents in the lowest or highest IQ bins are not the outliers driving the negative association. In untabulated results, we also repeat the analysis after excluding all inflation forecasts that equal zero. Although a value of zero is also rounded, one might argue that other considerations lead respondents to provide this number. No patterns change when we exclude all zeros from the analysis.

In Table 5, we run this analysis in a multivariate setting, in which we regress a dummy variable that equals 1 if the respondent provided a round number in his inflation forecast (columns (1)-(2)), and zero otherwise. The main covariate of interest is the dummy variable that equals 1 if the respondent obtained an IQ score of 6 or above.

Column (1) reports the raw correlation and column (2) controls for demographics and year-month fixed effects. Consistent with the patterns described above, we find that respondents in the top half of the distribution by IQ are 7.4 percentage points less likely to report round numbers. Because we control for income and college education, socioeconomic status is an unlikely driver of the association between IQ and rounding (Ben-David, Fermand, Kuhnen, and Li (2018)).

Rounding to salient thresholds might reflect objective uncertainty, for example due to high fluctuations in realized inflation, or subjective uncertainty about future states of the world and macroeconomic conditions (D'Acunto et al. (2018)). To the extent that the expectations of high-IQ men are more consistent with the rational benchmark, we might expect they have a higher propensity to round in times of high objective uncertainty about inflation. Instead, low-IQ men might round due to subjective uncertainty about inflation, irrespective of the extent of objective uncertainty. 
Based on the argument above, when inflation rates fluctuate substantially, both highIQ and low-IQ respondents might be uncertain and prone to rounding. Instead, when inflation uncertainty is low, high-IQ respondents might be less prone to rounding than low-IQ men. To test this hypothesis, we consider the standard deviation of monthly inflation rates within each year as a proxy for the objective inflation uncertainty in that year.

In Figure 6, we report the standard deviation in the form of gray bars, and measure it on the left y-axis. The black line plots, for each year, the difference in the average fraction of rounders between low-IQ men and high-IQ men. According to our conjecture, this difference should be high when inflation rates do not vary much, whereas it should be low when inflation rates vary substantially. Figure 6 is consistent with this pattern. The fraction of low-IQ rounders is relatively higher in years of low objective inflation uncertainty, such as 2006, 2007, and 2013. Instead, the fractions of low-IQ and high-IQ rounders are similar at times of high objective inflation uncertainty, such as 2001, 2003, and 2009.

\section{C.2 Implausible Values}

The second dimension of quality of expectations we consider is the tendency of respondents to provide implausible forecasts for inflation. Implausible forecasts are values that would be very unlikely to materialize over a period of 12 months based on historical inflation rates and the fact the European Central Bank has an inflation target of close to but below $2 \%$ in the medium run. We consider several thresholds for implausible forecasts. The thresholds are 5\%,7\%,10\%, and $12 \%$. For instance, for the $5 \%$ threshold, we would categorize an inflation forecast above $5 \%$ or below $-5 \%$ as implausible.

Figure 2 in the Introduction shows that, similar to the patterns for forecast errors for inflation and the extent of rounding, the share of respondents who report implausible values for the $5 \%$ threshold declines monotonically with IQ, ranging from $20 \%$ of respondents in the lowest IQ bin to $7 \%$ of respondents in the highest bin.

Because the 5\% threshold is arbitrary, in Figure 7, we report the fraction of respondents providing implausible values for different thresholds by IQ bin. In particular, we consider a 5\% threshold (solid line), a 7\% threshold (long-dashed line), a 10\% threshold (short-dashed line), and a $12 \%$ threshold (dash-dotted line). The Figure confirms the 
monotonic negative association between the fraction of respondents reporting implausible values for inflation forecasts and IQ levels for all the thresholds.

Another interesting pattern we observe in Figure 7 is the differential changes in the slopes of the curves at the lowest and highest IQ levels across different thresholds. Consider first the $5 \%$ threshold (top line). The curve is essentially flat for the 3 highest IQ bins suggesting no increasing marginal returns to IQ in terms of improving the quality of forecasts for the highest levels of IQ. Instead, for low levels of IQ, the curve is downward sloping and is steepest across the 3 lowest IQ bins, suggesting increasing marginal returns to IQ in terms of improving the quality of forecasts for the lowest levels of IQ. Interestingly, these two patterns are more pronounced when we consider more implausible thresholds. For instance, consider the $12 \%$ threshold (bottom line). In this case, the curve is even flatter across the intermediate and highest IQ bins, whereas it is even steeper for the lowest IQ bins. This qualitative pattern suggests the marginal returns to IQ in terms of improving the quality of forecasts are especially high the lower the quality of forecasts.

In columns (3) and (4) of Table 5, we run a multivariate analysis regressing a dummy variable that equals 1 if the respondent provided an implausible value for his inflation forecast, and zero otherwise. We use the threshold of $5 \%$ in this table, but all results are similar for the other thresholds. The main covariate of interest is a dummy variable that equals 1 if the respondent obtained an IQ score of 6 or above. High-IQ men are 2 percentage points less likely to report implausible values for inflation forecasts when we condition on observables and time-varying economic shocks.

Overall, we confirm the patterns by IQ we documented for forecast errors for inflation when we consider other potential proxies for the quality of inflation forecasts, such as rounding and reporting implausible values.

\section{IQ and Choice}

Do expectations of different quality transmit to individual choice, and especially consumption and saving decisions? Most existing models studying fiscal and monetary policy are based on a representative agent with rational expectations that reacts to changing economic incentives. Based on these premises, the Euler equation predicts a positive association between consumption expenditure and inflation expectations. In the textbook New Keynesian model, monetary policy affects real quantities through 
the dynamic IS equation, and hence, intertemporal substitution. In the second part of our analysis, we aim to test whether low-IQ and high-IQ individuals differ in the extent to which they update their consumption, saving, and borrowing plans to changing inflation expectations. This analysis is important because households' understanding of intertemporal substitution and its implications for consumption plans is crucial for any intertemporal-substitution-based channels to affect behavior.

Different mechanisms exist through which expectations might transmit to choice differently between high- and low-IQ men. One possibility is low-IQ individuals ultimately make consumption and saving decisions as if they held accurate inflation expectations even if they report expectations of lower quality once asked in a survey. Note the survey we use asks households about changes in consumer prices. The fact low-IQ individuals might not know the term "inflation" thus cannot drive our results. Yet, everyone might hold accurate and unbiased beliefs and make choices as representative-agent models prescribe, but low-IQ men might be unable to express their beliefs in numerical terms. If this conjecture were true, the inaccurate expectations of low-IQ individuals would not have substantial implications for individual-level or aggregate outcomes.

A second possibility is low-IQ individuals understand the concept of intertemporal substitution, but they rely on their inaccurate expectations when making choices. In this case, we would observe individuals' decisions deviating from the choices of the representative agent, but conditional on observing individual beliefs, one could predict how the individual would allocate his resources between current consumption and future consumption.

Finally, a third case is low-IQ individuals might not only have inaccurate expectations, but might also not know or understand the concept of intertemporal substitution.

\section{A. IQ and Intertemporal Substitution}

As documented in the previous section, low-IQ households provide numerical values for inflation expectations that are often inaccurate, implausible, or rounded. This fact is consistent with the common concern with survey-based numerical values of inflation expectations (e.g., see Binder (2015) and D'Acunto et al. (2018)). If we correlated numerical values of inflation expectations with choice, we would be unable to disentangle 
the case in which low-IQ households were unable to articulate their expectations in numerical terms from the case in which they were unable to understand intertemporal substitution, because in both cases, we would observe that reported numerical inflation expectations do not relate to consumption plans.

To address this concern, we follow D'Acunto, Hoang, and Weber (2018) and construct a measure of high inflation expectations based on survey respondents' qualitative expectations. The rationale is that, even if low-IQ households were not able to express their numerical inflation expectations meaningfully, they should be able to report whether they expect inflation to increase, stay the same, or decrease over the following 12 months. If not, they would either not understand the concept of inflation or would hold incorrect beliefs.

This qualitative measure of inflation expectations is a dummy variable that equals 1 if the respondent answers in the EU survey he expects a higher inflation rate in the following 12 months, compared to the prevailing inflation rate over the past 12 months, and zero otherwise. D'Acunto, Hoang, and Weber (2018) show this measure tracks closely ex-post realized inflation across several samples in different countries and different time periods. A rationale for why this qualitative measure might track ex-post realized inflation more closely than quantitative measures is that respondents might have a clear idea for the directional changes in inflation they perceive and expect, but might be uninformed about the level of inflation prevailing at the time they are interviewed (, consistent with evidence in (Vellekoop and Wiederholt (2017)).

We follow the recent literature in macroeconomics using micro data and study the association between the qualitative measure of inflation expectations and different choices (Bachmann et al. (2015) and Crump, Eusepi, Tambalotti, and Topa (2015)). Our first outcome variable of interest, households' readiness to purchase durable goods, derives from discrete, non-ordered choices in a survey. We therefore model the response probabilities in a multinomial-logit setting. We assume the answer to the question on the readiness to spend is a random variable representing the underlying population.

We estimate the model via maximum likelihood to obtain the vector of coefficients and compute the marginal effects of changes in the covariates on the probability that individuals choose any of three answers in the survey, and report them in the tables.

In columns (1)-(2) of Table 6, we report the average marginal effects for whether respondents think it is a good time to purchase durable goods on the dummy that equals 
1 if the respondent thinks inflation will be higher in the following 12 months than it was in the previous 12 months. We cluster standard errors at the quarter level to allow for correlation of unknown form in the residuals across contiguous months. Both specifications include the full set of demographic controls we observe, as well as controls for past realized inflation (Jonung (1981)). The results in column (1) refer to the full sample of high-IQ men and those in column (2) include the full sample of low-IQ men. In column (1), high-IQ men who expect inflation to increase are on average $3.6 \%$ more likely to answer it is a good time to buy durables than do high-IQ men who expect constant or decreasing inflation. Instead, column (2) documents no economically or statistically significant association between the inflation expectations and the readiness of low-IQ men to purchase durable goods. If anything, the estimated coefficient is negative, although small in size and not statistically distinguishable from zero.

These baseline results are consistent with the possibility that low-IQ men do not understand the concept of intertemporal substitution because they do not adjust their consumption plans to their inflation expectations. Recall we use the dummy variable for expected inflation from a qualitative question which measures the change in expected inflation and tracks actual realized inflation well both for high-IQ and low-IQ men (D'Acunto, Hoang, and Weber (2018)). Hence, these results are barely consistent with the idea of low-IQ men being sophisticated - knowing their quantitative inflation expectations are inaccurate and deciding willingly not to react to them when forming purchasing plans. If they were sophisticated, they would follow their expected directional change in inflation and adjust upward their consumption propensity when expecting higher inflation.

In the rest of Table 6 , we consider the sample splits we proposed in the analysis of the association between IQ and expectations in Table 3 to assess whether similar patterns arise for the case of purchasing plans. For each sample split reported on top of the columns, we report four marginal effects: for those high-IQ and low-IQ men who belong to the reported category (Panel A) and for those who do not belong to the category (Panel B).

We emphasize a set of patterns from these sample splits. First, for most of the splits we consider, high-IQ men who expect higher inflation are systematically more likely to respond it is a good time to purchase durable goods irrespective of whether they belong to the demographic group of interest or not. Columns (3), (5), (7), (9), (11), and (13) show that this higher propensity is economically large irrespective of whether or not high-IQ men are single, live in urban areas, are above the median of the distribution by income, 
have a college degree, or have an economics or business degree. Note we fail to detect statistical significance at conventional levels for the coefficients associated with high-IQ men above 35, high-IQ men below the median of the income distribution, and high-IQ men with an economics or business degree, but even in these cases the point estimates are positive and large.

Second, we fail to reject the null the marginal effect equals zero for low-IQ respondents across most demographic splits, irrespective of the sample size, both economically and statistically (see columns (4), (6), (8), (10), and (12)).

Third, low-IQ men with an economics or business degree are the only group of low-IQ men for whom we can detect an economically and statistically positive association between expecting higher inflation and answering it is a good time to purchase durable goods, as the consumer Euler equation implies (0.1109, see column (14), Panel A). ${ }^{10}$ This result might suggest that providing economics and business knowledge to low-IQ men might be a relevant substitute to cognitive abilities in determining economic choice.

\section{B. IQ, Borrowing Motives, and Saving Motives}

In the last part of this section, we assess whether low-IQ men differ from high-IQ men even along other forward-looking choices. To this aim, we exploit a limited set of questions in the survey regarding households' motives to save and borrow. These questions are conditional on saving and borrowing and hence, we observe smaller and varying sample sizes. The structure is such that individuals are asked whether they plan to save (borrow), and if they respond yes, various subquestions regarding the motives of saving (borrowing) follow.

High-IQ men might understand the trade-off between present and future consumption better than low-IQ men or might be more patient (Falk et al. (2018)). In both cases, we should observe high-IQ men save more for retirement than low-IQ men.

We first assess whether individuals differ - based on cognitive abilities - in their propensity to save. Column (1) of Table 7 reports the marginal effect attached to the high-IQ dummy when the outcome variable of a probit specification is a dummy that

\footnotetext{
${ }^{10}$ Note the coefficient is also positive and nonnegligible in size for low-IQ men with any college degree (see column (12), Panel A), but we fail to reject the null that this coefficient is zero statistically. Because this group also includes economics and business college degrees, it is unlikely the association is positive and large for low-IQ respondents with other types of college degrees.
} 
equals 1 if the individual claims he saves at least part of his monthly labor income. High-IQ individuals, if anything, are less likely to save than low-IQ men. This fact could be consistent with a reduced precautionary savings motive for high-IQ men among other potential explanations.

We then consider a second question that digs deeper into the saving motives and asks respondents whether they save for retirement. In column (2), we report the marginal effect on the high-IQ dummy for a similar specification as column (1), but in this case, the outcome variable is a dummy that equals 1 if the respondent claims he saves for retirement. The size of the association flips, and the association with high IQ becomes positive and statistically different from zero. Overall, then, the analysis of saving motives suggests high-IQ men are, if anything, less likely to save in general, but they are more likely to save for retirement than low-IQ men. We interpret this evidence as consistent with the notion that high-IQ men are more forward-looking than low-IQ men.

After having assessed whether any differences exist in the average association between being in the top of the IQ distribution and saving for retirement, in Figure 8 we provide evidence that the association between IQ bins and the fraction of households that declare they save for retirement increases monotonically - it is lowest for the first IQ bin and highest for the top IQ bins. Because the sample size is smaller than in our baseline analysis, statistical significance is sparse and we cannot reject the null hypothesis fractions are the same across all adjacent bins.

We move on to consider borrowing motives. In this analysis, we compare respondents' likelihood of answering that they plan to borrow to finance current or future consumption with the likelihood of answering that they plan to borrow to finance current or future education-related expenses. Column (3) of Table 7 shows high-IQ men do not differ from low-IQ men in their likelihood of borrowing to finance consumption, whereas we see in column (4) high-IQ men are substantially more likely than low-IQ men to plan to borrow to finance education-related costs. We interpret this evidence as also consistent with high-IQ individuals being more forward-looking than low-IQ individuals, because they plan to borrow to finance a long-term-return investment in human capital. This interpretation assumes formal education and IQ are at least in part substitutes. 


\section{Conclusion}

Substantial variation exists in economic expectations across individuals and over time, and expectations often deviate from the full-information rational-expectations benchmark. We document cognitive abilities play a central role for forecast errors of inflation, uncertainty in forecasts, and for forecasting implausible values in a large, representative population. We also show cognitive abilities are systematically related to individuals' plans for current and future consumption, their understanding of intertemporal substitution, and their forward-looking behavior, such as the choice of saving for retirement or the choice of borrowing to finance education-related expenses and not only current consumption. One notable exception are those low-cognitive ability men with a business or economics degree who have more accurate inflation expectations and adjust their consumption plans upward when expecting higher inflation as the consumer Euler equation prescribes. These results might suggest a role for basic economics education to improve the forecasts and choice of the broader population.

Future research in economics, finance, and cognitive science should investigate the specific cognitive mechanisms that explain the role of cognitive abilities in the formation of economic expectations. For instance, do cognitive abilities matter for the gathering of information, the processing of information, and the mapping of processed values into economic decisions? Or are they only driving choice through a subset of these channels? Distinguishing between these mechanisms is relevant to inform the development of new heterogeneous-agent models across fields of economics.

The lack of forward-looking attitudes in low-cognitive-ability individuals might result in a lower sensitivity of their choices to policy shocks that operate through forward-looking savings, consumption, and borrowing choices, and might help explain why some policies are less effective than a representative-agent model predicts, such as forward guidance. Limited reaction to policy interventions by many households would be detrimental for governments that aim to change aggregate consumption and saving patterns throughout the business cycle (D'Acunto et al. (2018)). Future research could thus investigate the extent to which cognitive abilities interact with the reaction to policy interventions and quantify their effect on aggregate outcomes. 


\section{References}

Agarwal, S. and B. Mazumder (2013). Cognitive abilities and household financial decision making. American Economic Journal: Applied Economics 5(1), 193-207.

Aghion, P., U. Akcigit, A. Hyytinen, and O. Toivanen (2017). The social origins of inventors. NBER Working Paper 24110.

Bachmann, R., T. O. Berg, and E. Sims (2015). Inflation expectations and readiness to spend: Cross-sectional evidence. American Economic Journal: Economic Policy 7(1), $1-35$.

Ben-David, I., E. Fermand, C. Kuhnen, and G. Li (2018). Expectations uncertainty and household financial choices. Working Paper.

Bernanke, B. S. (2007). Inflation expectations and inflation forecasting. Speech 306, Board of Governors of the Federal Reserve System (U.S.).

Binder, C. (2015). Consumer inflation uncertainty and the macroeconomy: Evidence from a new micro-level measure. Unpublished Manuscript, UC Berkeley.

Binder, C. (2017). Measuring uncertainty based on rounding: New method and an application to inflation expectations. Journal of Monetary Economics 90, 1-12.

Bordalo, P., N. Gennaioli, and A. Shleifer (2018). Diagnostic expectations and credit cycles. The Journal of Finance 73(1), 199-227.

Coibion, O., Y. Gorodnichenko, and R. Kamdar (2018). The formation of expectations, inflation, and the phillips curve. Journal of Economic Literature 56(4), 1447-1491.

Coibion, O., Y. Gorodnichenko, and S. Kumar (2018). How do firms form their expectations? New survey evidence. American Economic Review 108(9), 2671-2713.

Coibion, O., Y. Gorodnichenko, and M. Weber (2019). Monetary policy communications and their effects on household inflation expectations. Working Paper.

Crump, R. K., S. Eusepi, A. Tambalotti, and G. Topa (2015). Subjective intertemporal substitution. FRB of New York Staff Report (734).

D'Acunto, F., D. Hoang, M. Paloviita, and M. Weber (2018). Human frictions to the transmission of economic policy. Working Paper.

D'Acunto, F., D. Hoang, and M. Weber (2018). The effect of unconventional fiscal policy on consumption expenditure. Working Paper.

D'Acunto, F., U. Malmendier, J. Ospina, and M. Weber (2018). Salient price changes, inflation expectations, and household behavior. Unpublished manuscript, University of Chicago Booth School of Business.

Dal Bo, E., F. Finan, O. Folke, T. Persson, and J. Rickne (2017). Who becomes a politician? Quarterly Journal of Economics 132(4), 1877-1914.

Das, S., C. Kuhnen, and S. Nagel (2017). Socioeconomic status and macroeconomic expectations. Working Paper.

Diether, K. B., C. J. Malloy, and A. Scherbina (2002). Differences of opinion and the cross section of stock returns. The Journal of Finance 57(5), 2113-2141.

Falk, A., A. Becker, T. Dohmen, B. Enke, D. Huffman, and U. Sunde (2018). Global evidence on economic preferences. Quarterly Journal of Economics, forthcoming 133(4), $1645-1692$.

Gennaioli, N., Y. Ma, and A. Shleifer (2018). Over-reaction in macroeconomic expectations. NBER Working Paper No. 24932.

Gennaioli, N. and A. Shleifer (2018). A crisis of beliefs: Investor psychology and financial fragility. Princeton University Press.

Grinblatt, M., S. Ikäheimo, M. Keloharju, and S. Knüpfer (2016). IQ and mutual fund choice. Management Science 62(4), 924-944.

Grinblatt, M., M. Keloharju, and J. Linnainmaa (2011). IQ and stock market 
participation. The Journal of Finance 66 (6), 2121-2164.

Grinblatt, M., M. Keloharju, and J. T. Linnainmaa (2012). IQ, trading behavior, and performance. Journal of Financial Economics 104(2), 339-362.

Jonung, L. (1981). Perceived and expected rates of inflation in Sweden. The American Economic Review 71(5), 961-968.

Landier, A., Y. Ma, and D. Thesmar (2018). New experimental evidence on expectations formation. Working Paper.

Malmendier, U. and S. Nagel (2016). Learning from inflation experiences. Quarterly Journal of Economics 131(1), 53-87.

Manski, C. and F. Molinari (2010). Rounding probabilistic expectations in surveys. Journal of Business Economics and Statistics 28(2), 219-231.

Manski, C. F. (2004). Measuring expectations. Econometrica 72(5), 1329-1376.

Roth, C. and J. Wohlfart (2018). How do expectations about the macroeconomy affect personal expectations and behavior? Working Paper.

Vellekoop, N. and M. Wiederholt (2017). Inflation expectations and choices of households: Evidence from matched survey and administrative data. Unpublished Manuscript, University of Frankfurt.

Yellen, J. (2016). Macroeconomic research after the crisis. Speech at the 60th annual economic conference sponsored by the Federal Reserve Bank of Boston.

Zeldes, S. P. (1989). Consumption and liquidity constraints: An empirical investigation. The Journal of Political Economy 97(2), 305-346. 
Figure 3: Average Forecast Error by IQ

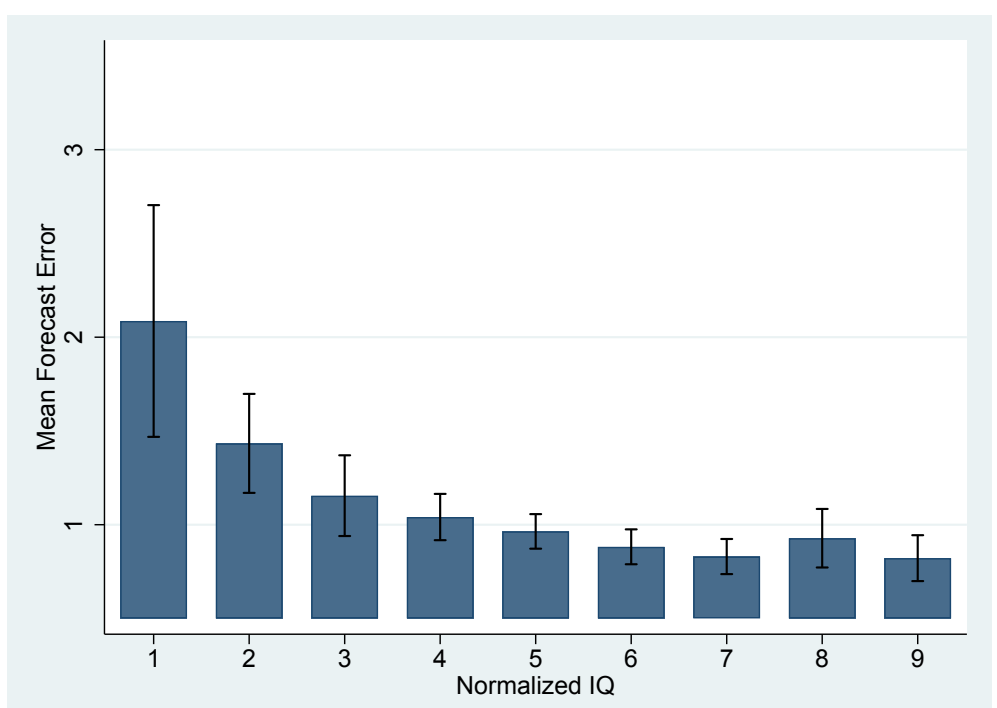

This figure plots the average forecast error for inflation as a function of normalized IQ in Finland. Forecast errors is the difference between inflation expectations and ex-post realized inflation. Perception error is the difference between perceived inflation over the previous 12 months and actual inflation over the same period. We use the confidential micro data underlying the official European Commission consumer confidence survey to measure inflation expectations. Statistics Finland asks a representative sample of 1,500 households how consumer prices will evolve in the next 12 months. We measure normalized IQ using data from the official military entrance exam in Finland. The sample period is January 2001 to March 2015. 
Figure 4: Average Forecast Error by Income and Education Levels

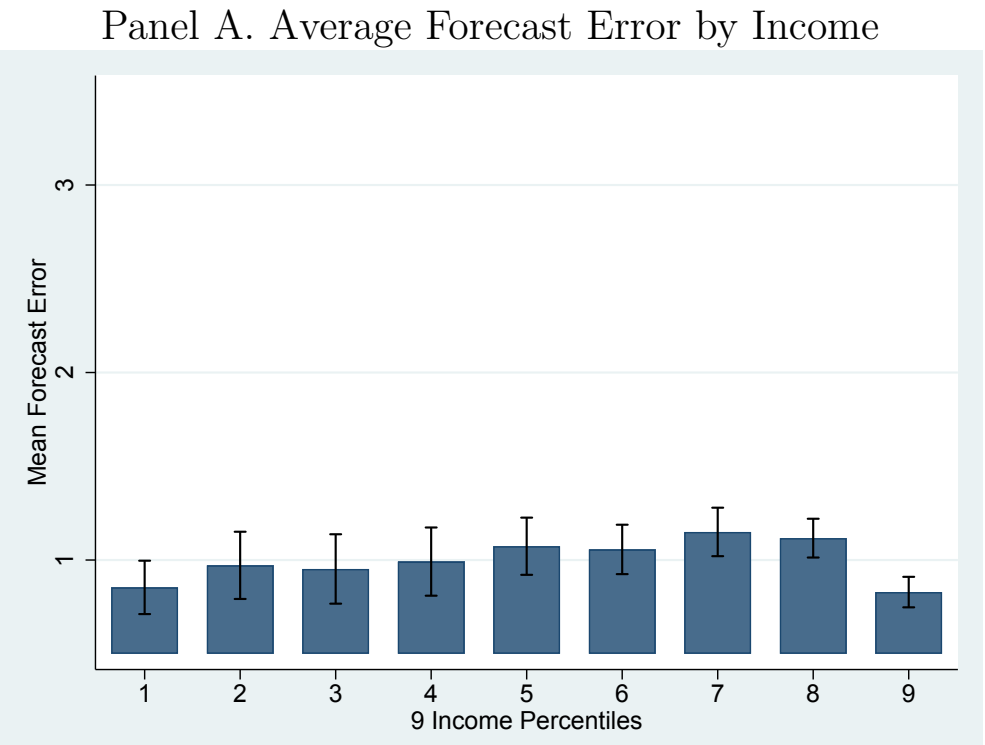

Panel B. Average Forecast Error by Education

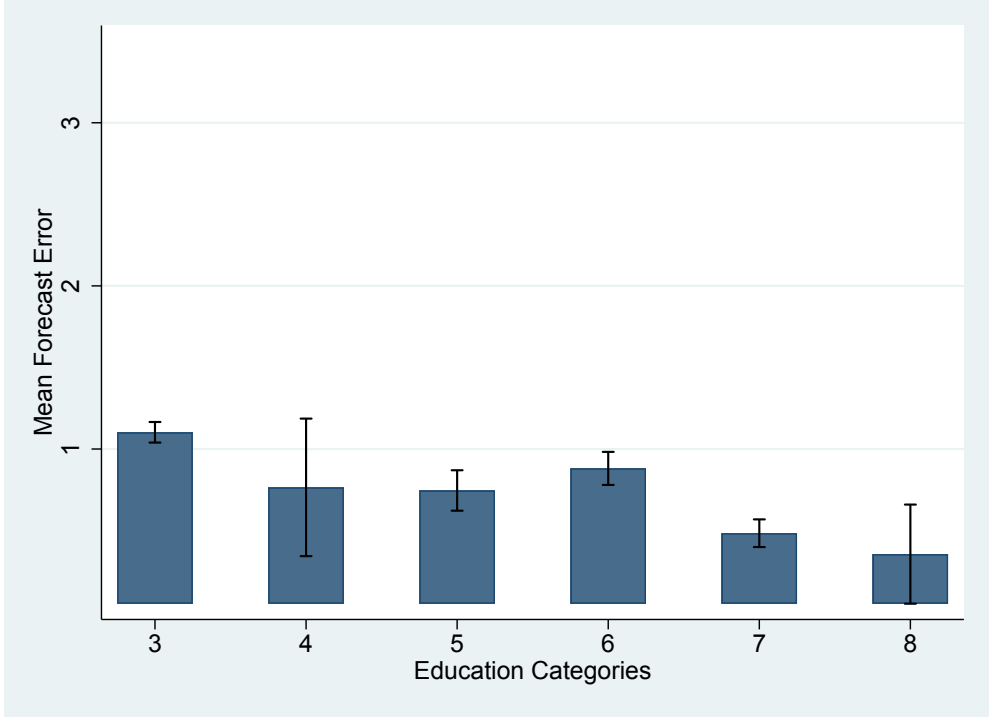

Panel $A$ of this figure plots the average inflation forecast error as a function of 9 income percentiles in Finland. Panel B plots the average inflation forecast error across 6 education categories. Education levels are based on the International Standard Classification of Education. We define forecast errors as differences between inflation expectations and ex-post realized inflation. We use the confidential micro data underlying the official European Commission consumer confidence survey to measure inflation expectations. Statistics Finland asks a representative sample of 1,500 households how consumer prices will evolve in the next 12 months. The sample period is January 2001 to March 2015. 


\section{Figure 5: Dispersion of Forecasts of Inflation by IQ}

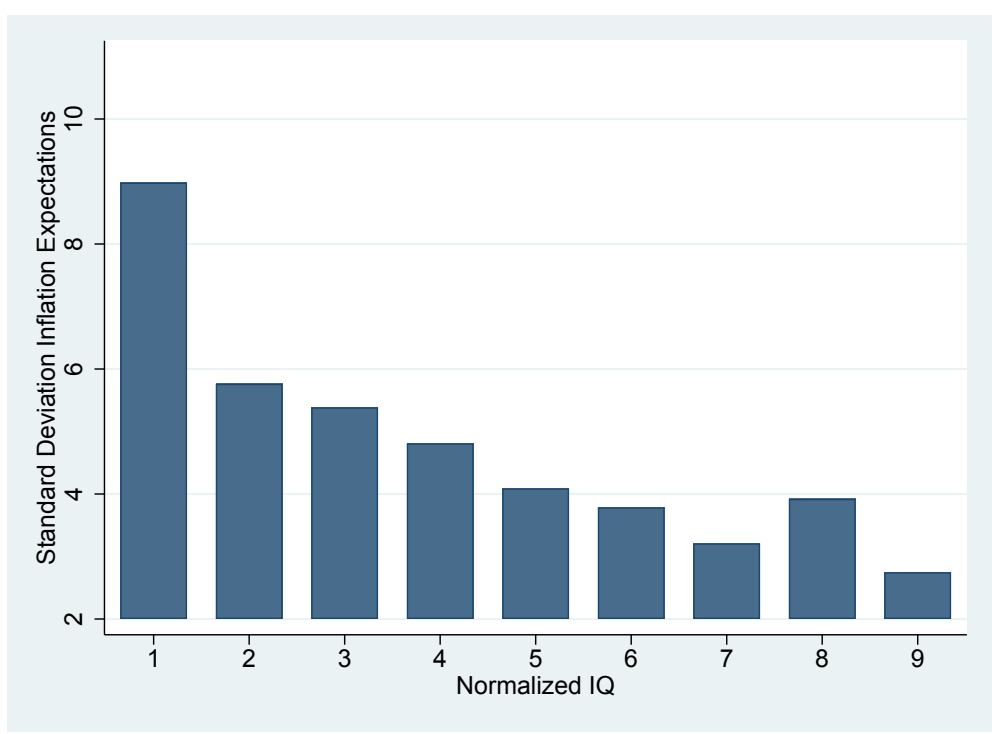

This figure plots the standard deviation of inflation forecasts as a function of normalized IQ in Finland. We use the confidential micro data underlying the official European Commission consumer confidence survey to measure inflation forecasts and perception. We measure normalized IQ using data from the official military entrance exam in Finland. The sample period is January 2001 to March 2015. 
Figure 6: Yearly Standard Deviation of Monthly Inflation Rates and Fraction of Rounders

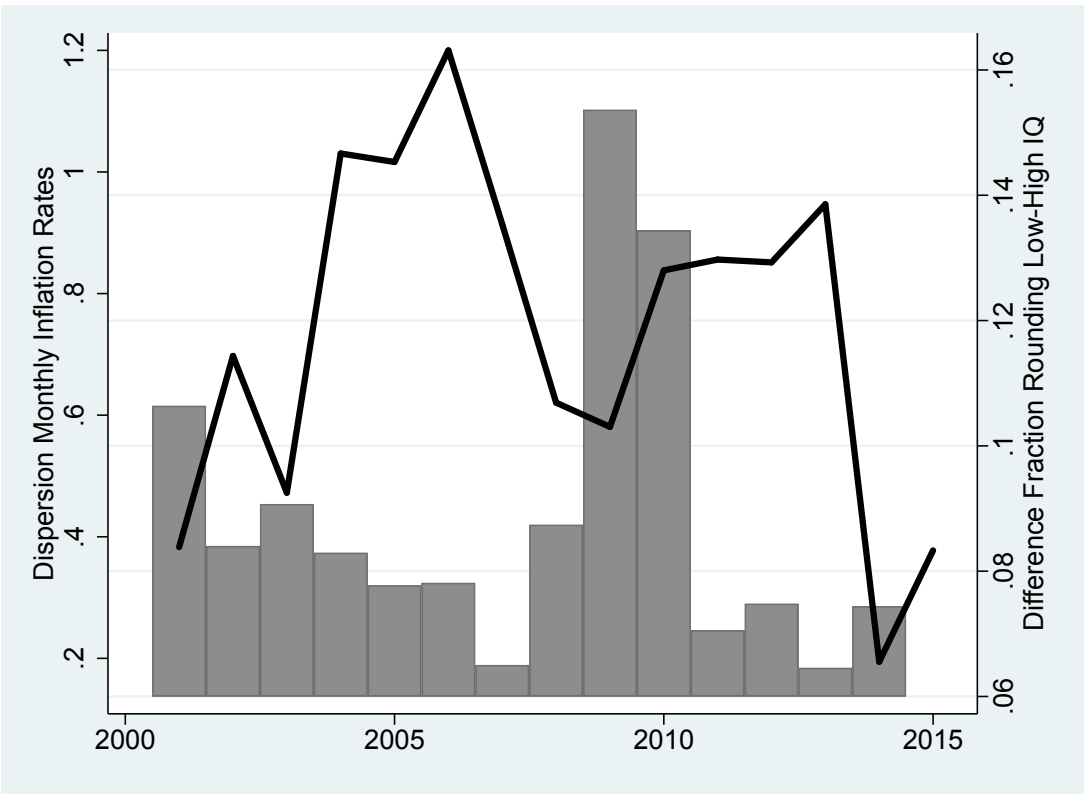

This figure plots the standard deviation of realized inflation within a year on the left $y$-axis and the differences in the fraction of rounders between low- and high-IQ men. We define rounders as survey participants who report multiples of 5 for the numeric inflation forecast. We use the confidential micro data underlying the official European Commission consumer confidence survey to measure inflation forecasts and perception. We measure normalized IQ using data from the official military entrance exam in Finland. IQ is a standardized variable between 1 and 9 . High IQ reflects a normalized IQ larger than 5. The sample period is January 2001 to March 2015. 
Figure 7: Implausible Values for Inflation Expectations by IQ

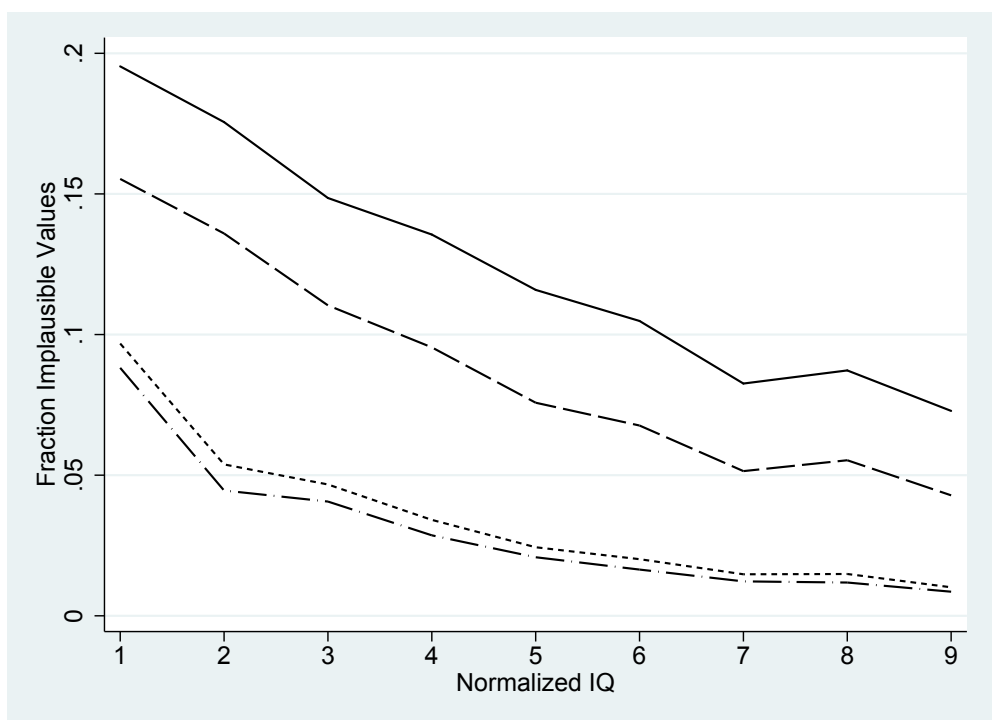

This figure plots the share of survey respondents who report forecasts for inflation larger than a threhold in absolute value by IQ levels. The thresholds we consider are 5\% (solid line), $7 \%$ (long-dashed line), 10\% (short-dashed line), and 12\% (dash-dotted line). IQ is the standardized test score from the military entrance exam test for all men in Finland. $I Q$ obtains integer values between 1 and 9. The sample period is from January 2001 to March 2015. 
Figure 8: Fraction of Forward-Looking Households by IQ

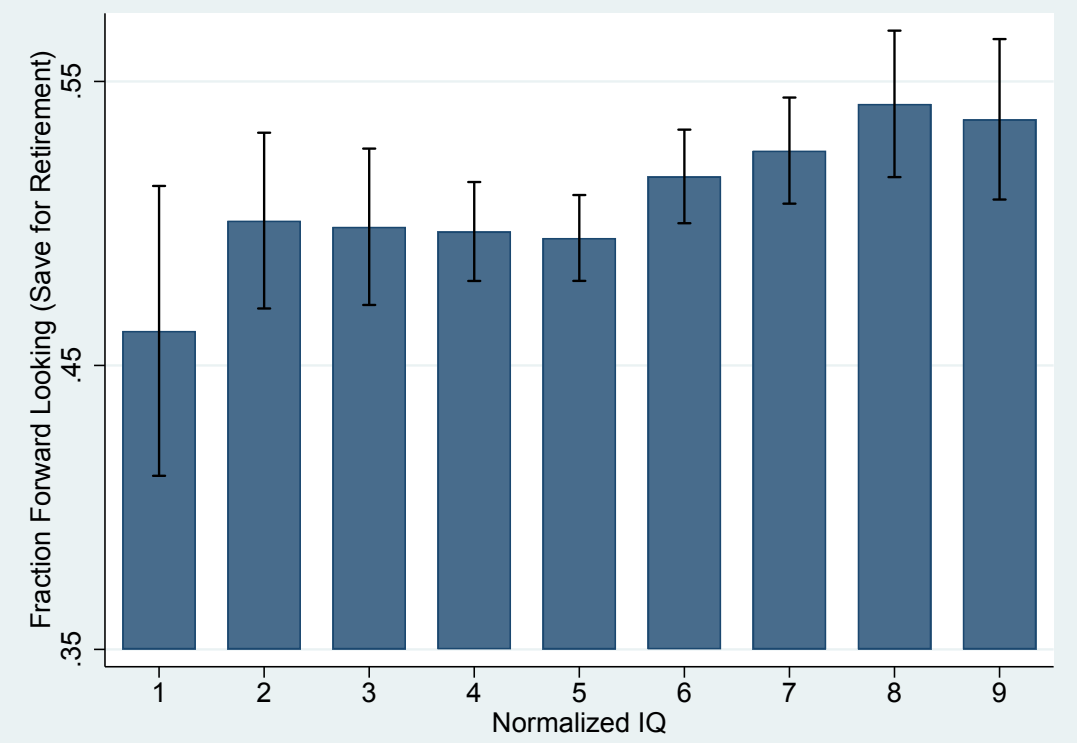

This figure plots the share of households that report they save for retirement (conditional on saving in general) as a function of normalized IQ in Finland. We consider saving for retirement conditional on saving to be a proxy for whether households are forward-looking. We use the confidential micro data underlying the official European Commission consumer confidence survey to measure inflation expectations. Statistics Finland asks a representative sample of 1,500 households how consumer prices will evolve in the next 12 months. We measure normalized $I Q$ using data from the official military entrance exam in Finland. The sample period is January 2001 to March 2015. 


\section{Table 1: Descriptive Statistics}

This table reports descriptive statistics for the variables we use in the paper. We use the confidential micro data underlying the official European Commission consumer confidence survey to construct these variables. We measure normalized IQ using data from the official military entrance exam in Finland. The sample period is January 2001 to March 2015.

\begin{tabular}{|c|c|c|c|c|c|c|}
\hline Statistic & $\begin{array}{c}\text { Inflation } \\
\text { Perception }\end{array}$ & $\begin{array}{c}\text { Inflation } \\
\text { Expectation }\end{array}$ & $\begin{array}{l}\text { Total Debt } \\
\text { [EUR] }\end{array}$ & $\begin{array}{c}\text { IQ } \\
\text { Dummy }\end{array}$ & Age & $\begin{array}{c}\text { Income } \\
\text { [EUR] }\end{array}$ \\
\hline Nobs & 27,184 & 27,568 & 27,540 & 27,568 & 27,568 & 27,568 \\
\hline Mean & 3.00 & 2.47 & 38,591 & 0.50 & 30.70 & 22,541 \\
\hline Std & 4.63 & 3.76 & 53,806 & 0.50 & 6.94 & 14,301 \\
\hline $\mathrm{p} 1$ & -5.00 & -5.00 & 0 & 0 & 19 & 900 \\
\hline p10 & 0.00 & 0.00 & 0 & 0 & 21 & 6,700 \\
\hline p25 & 0.00 & 0.00 & 0 & 0 & 25 & 13,100 \\
\hline p50 & 2.00 & 2.00 & 14,400 & 1 & 30 & 21,000 \\
\hline p75 & 5.00 & 3.50 & 62,300 & 1 & 36 & 28,900 \\
\hline p90 & 7.00 & 5.00 & 102,200 & 1 & 40 & 38,300 \\
\hline p99 & 20.00 & 15.00 & 242,400 & 1 & 46 & 74,400 \\
\hline \multirow[t]{2}{*}{ Single } & no & $38.93 \%$ & Urban & & no & $64.41 \%$ \\
\hline & yes & $61.07 \%$ & & & yes & $35.59 \%$ \\
\hline \multirow[t]{2}{*}{ Unemployed } & no & $94.17 \%$ & Helsinki & & no & $72.19 \%$ \\
\hline & yes & $5.83 \%$ & & & yes & $27.81 \%$ \\
\hline \multirow[t]{2}{*}{ Kids } & no & $22.41 \%$ & College & & no & $65.67 \%$ \\
\hline & yes & $77.59 \%$ & & & yes & $34.33 \%$ \\
\hline \multirow[t]{2}{*}{ Rounders } & no & $59.00 \%$ & Save & & no & $27.70 \%$ \\
\hline & yes & $41.00 \%$ & & & yes & $72.30 \%$ \\
\hline Implausible & no & $89.80 \%$ & Save & & no & $70.53 \%$ \\
\hline Values & yes & $10.20 \%$ & Retirement & & yes & $29.47 \%$ \\
\hline \multirow[t]{5}{*}{ Durables } & Good time & $50.94 \%$ & Borrow & & no & $85.04 \%$ \\
\hline & Neutral & $28.67 \%$ & Education & & yes & $14.96 \%$ \\
\hline & Bad time & $20.40 \%$ & & & & \\
\hline & & & Borrow & & no & $68.66 \%$ \\
\hline & & & Consumption & & yes & $31.34 \%$ \\
\hline
\end{tabular}


Table 2: Numerical Inflation Expectations by IQ

This table reports the average and standard deviation of inflation expectation by IQ category. We use the confidential micro data underlying the official European Commission consumer confidence survey to measure inflation expectations. We measure normalized IQ using data from the official military entrance exam in Finland. The sample period is January 2001 to March 2015.

\begin{tabular}{lccccccccccc}
\hline & \multicolumn{4}{c}{ Low-IQ Men } & & \multicolumn{4}{c}{ High-IQ Men } \\
\cline { 2 - 4 } \cline { 9 - 11 } IQ & 1 & 2 & 3 & 4 & 5 & & 6 & 7 & 8 & 9 \\
\hline Mean & 3.46 & 2.80 & 2.58 & 2.42 & 2.40 & & 2.36 & 2.28 & 2.30 & 2.26 \\
Std & 8.70 & 5.93 & 5.52 & 4.66 & 4.66 & & 4.16 & 3.47 & 4.13 & 3.31 \\
Nobs & 928 & 2,221 & 2,860 & 7,011 & 9,528 & & 8,099 & 6,030 & 3,213 & 2,688 \\
\hline
\end{tabular}




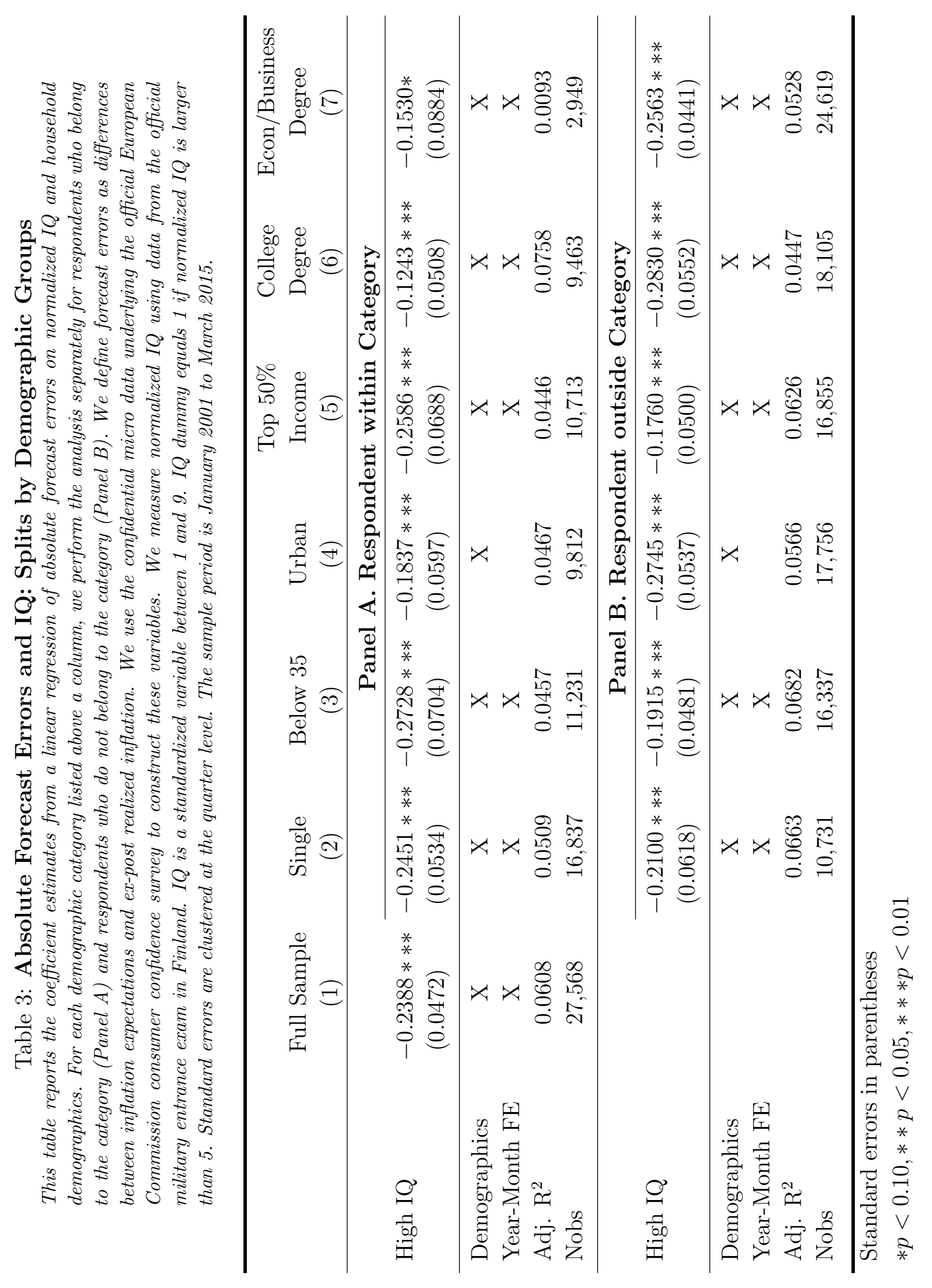




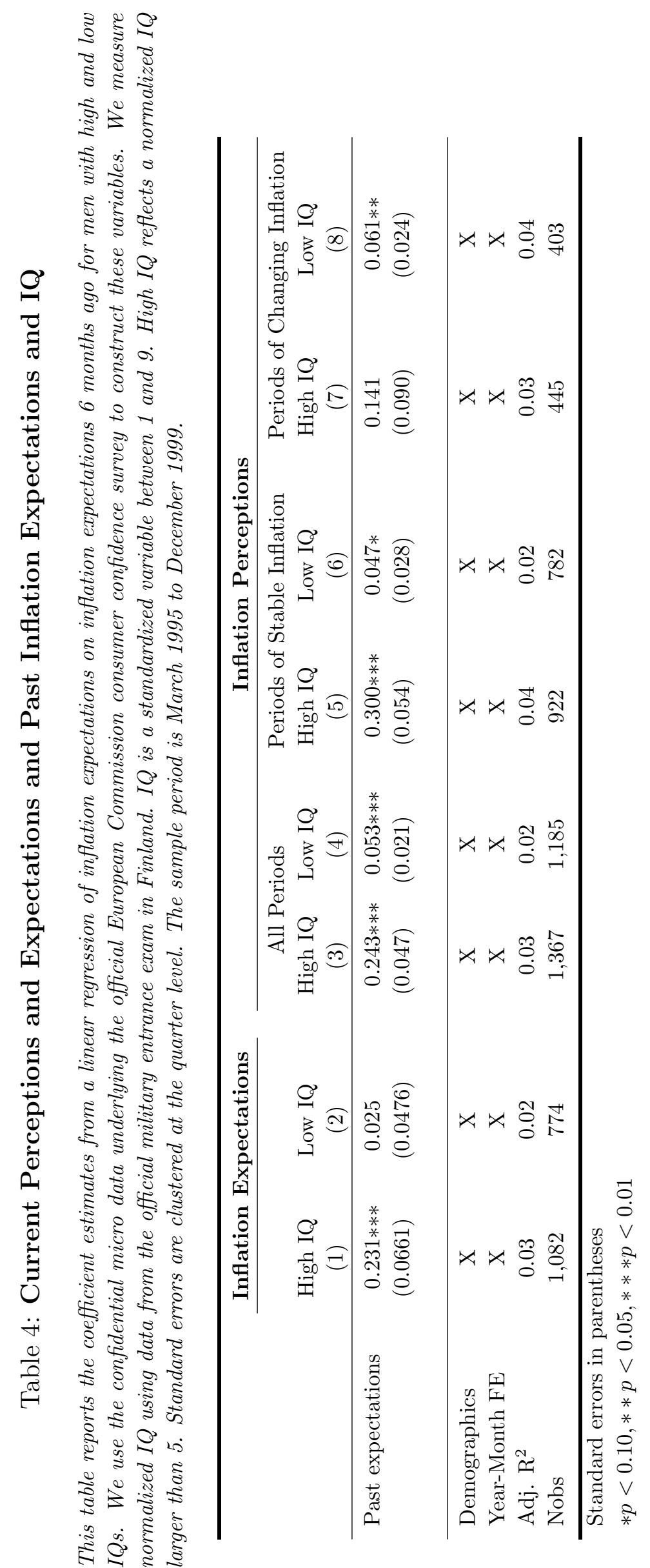




\section{Table 5: Rounding, Implausible Values, and Cognitive Abilities}

This table reports the coefficient estimates from a linear regression of a dummy variable that, for men with high and low IQs, equals 1 if the respondent reported a multiple of 5 as his inflation forecast and if he reported a number larger than 5 in absolute value as his inflation forecast. We use the confidential micro data underlying the official European Commission consumer confidence survey to construct these variables. We measure normalized IQ using data from the official military entrance exam in Finland. IQ is a standardized variable between 1 and 9. High IQ reflects a normalized IQ larger than 5. Standard errors are clustered at the quarter level. The sample period is January 2001 to March 2015.

\begin{tabular}{|c|c|c|c|c|}
\hline & \multicolumn{2}{|c|}{ Rounding } & \multicolumn{2}{|c|}{ Implausible Values } \\
\hline & (1) & $(2)$ & $(3)$ & (4) \\
\hline High IQ & $\begin{array}{c}-0.1195 * * * \\
(0.0051)\end{array}$ & $\begin{array}{c}-0.0735 * * * \\
(0.0061)\end{array}$ & $\begin{array}{c}-0.0446 * * * \\
(0.0036)\end{array}$ & $\begin{array}{c}-0.0194 * * * \\
(0.0044)\end{array}$ \\
\hline Demographics & & $\mathrm{X}$ & & $\mathrm{X}$ \\
\hline Year-Month FE & & $\mathrm{X}$ & & $\mathrm{X}$ \\
\hline Adj. $R^{2}$ & 0.0142 & 0.0482 & 0.0049 & 0.0417 \\
\hline Nobs & 38,289 & 28,807 & 31,841 & 24,345 \\
\hline
\end{tabular}

Standard errors in parentheses

$* p<0.10, * * p<0.05, * * * p<0.01$ 


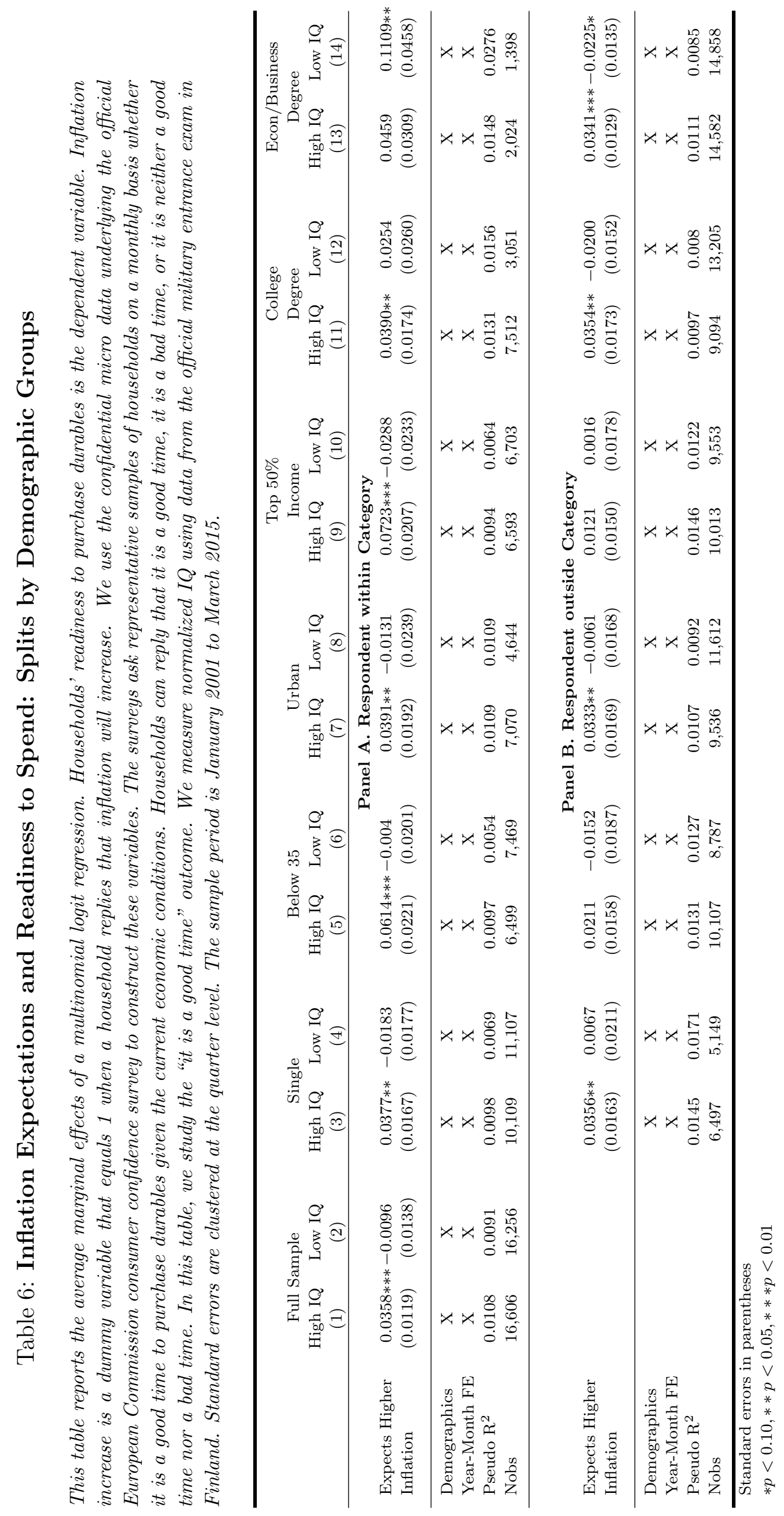




\section{Table 7: Saving and Borrowing Motives and Cognitive Abilities}

This table reports the average marginal effects of individuals' saving and borrowing motives. Individuals' saving and borrowing motives are the dependent variables that equal dummy variables that equal 1 if the respondent agrees with the statement. We use the confidential micro data underlying the official European Commission consumer confidence survey to construct these variables. We measure normalized IQ using data from the official military entrance exam in Finland. Standard errors are clustered at the quarter level. The sample period is January 2001 to March 2015.

\section{Saving Motives}

for any purpose for retirement

(1)

$(0.0200)$

(2)

$\begin{array}{ccc}\text { High IQ } & -0.1069 * * * & 0.1045 * * * \\ (0.0200) & (0.0287)\end{array}$

High IQ

\begin{tabular}{lcccc}
\hline Demographics & $\mathrm{X}$ & $\mathrm{X}$ & $\mathrm{X}$ & $\mathrm{X}$ \\
Year-Month FE & $\mathrm{X}$ & $\mathrm{X}$ & $\mathrm{X}$ & $\mathrm{X}$ \\
Pseudo R $^{2}$ & 0.0046 & 0.0482 & 0.0795 & 0.0259 \\
Nobs & 33,456 & 13,886 & 4,153 & 4,155 \\
\hline
\end{tabular}

Standard errors in parentheses

$* p<0.10, * * p<0.05, * * * p<0.01$ 


\section{Working Paper Series in Economics}

recent issues

No. 127 Francesco D'Acunto, Daniel Hoang, Maritta Paloviita and Michael Weber: IQ, expectations, and choice, January 2019

No. 126 Francesco D'Acunto, Daniel Hoang, Maritta Paloviita and Michael Weber: Cognitive abilities and inflation expectations, January 2019

No. 125 Rebekka Buse, Melanie Schienle and Jörg Urban: Effectiveness of policy and regulation in European sovereign credit risk markets - A network analysis, January 2019

No. 124 Chong Liang and Melanie Schienle: Determination of vector error correction models in high dimensions, January 2019

No. 123 Rebekka Buse and Melanie Schienle: Measuring connectedness of euro area sovereign risk, January 2019

No. 122 Carsten Bormann and Melanie Schienle: Detecting structural differences in tail dependence of financial time series, January 2019

No. 121 Christian Conrad and Melanie Schienle: Testing for an omitted multiplicative long-term component in GARCH models, January 2019

No. 120 Marta Serra-Garcia and Nora Szech: The (in)elasticity of moral ignorance, December 2018

No. 119 Thomas Mariotti, Nikolaus Schweizer, Nora Szech and Jonas von Wangenheim: Information nudges and self-control, November 2018

No. 118 Andranik S. Tangian: Methodological notes on composite indicators for monitoring working conditions, October 2018

No. 117 Andranik S. Tangian: Testing the improved third vote during the 2018 election of the Karlsruhe Institute of Technology student parliament, September 2018 